\title{
New compounds in the management of venous thromboembolism after orthopedic surgery: focus on rivaroxaban
}

\author{
Lars Carl Borris \\ Department of Orthopaedic Surgery, \\ Åarhus University Hospital, Åarhus, \\ Denmark
}

\begin{abstract}
Rivaroxaban $\left(\right.$ Xarelto $\left.^{\circledR}\right)$ is a member of a new class of oral, direct (antithrombinindependent) factor Xa inhibitors, which restrict thrombin generation both in vitro and in vivo. After oral administration the absorption is near $100 \%$, the bioavailability is near $80 \%$, and the elimination half-life is 5-9 hours with mixed excretion via the renal and fecal/biliary routes. The pharmacokinetics of rivaroxaban are predictable and consistent with a rapid onset of antithrombotic action within 2 hours after administration. Phase II clinical studies have been carried out in patients undergoing total hip arthroplasty (THA) or total knee arthroplasty (TKA) and a dose of $10 \mathrm{mg}$ once daily for thromboprophylaxis was selected for further clinical development. The results of the phase III studies showed a significantly better antithrombotic efficacy of rivaroxaban compared with enoxaparin both in the short term (10-14 days) in TKA patients and long term ( $35 \pm 4$ days) in THA patients with a comparable safety. Symptomatic thromboembolic events were also significantly reduced with rivaroxaban. Liver enzyme elevation was seen in patients treated with rivaroxaban, but there was no indication of an increased risk of liver toxicity compared with enoxaparin. In conclusion, rivaroxaban is a potent and safe new compound for antithrombotic prophylaxis in orthopedic surgery.

Keywords: deep vein thrombosis, oral direct factor Xa inhibitor, pulmonary embolism, rivaroxaban, thromboprophylaxis, total hip arthroplasty, total knee arthroplasty
\end{abstract}

\section{Introduction}

Total hip arthroplasty (THA) and total knee arthroplasty (TKA) are operations with a high risk of venous thromboembolic (VTE) complications and in the latest ACCP guidelines it is recommended to use prophylaxis with a low-molecular-weight heparin (LMWH), fondaparinux (a synthetic pentasaccharide) or adjusted-dose vitamin $\mathrm{K}$ antagonist (VKA) for at least 10 days after operation and to give extended prophylaxis for 28-35 days after THA and hip fracture surgery (Geerts et al 2004). Administration of LMWH and fondaparinux is subcutaneous and therefore these drugs are less suited for self-administration after discharge. Extended prophylaxis with enoxaparin after THA was cost-effective only when more than half of all patients were able to self-inject their treatment (Bergqvist and Johnsson 1999). Although administered orally, VKA is inconvenient to use due to the narrow therapeutic window and the need for repeated dose adjustments requiring laboratory monitoring. Thus, it has long been hoped that more convenient oral antithrombotic drugs would be discovered. The first step in this direction was when ximelagatran, an oral direct thrombin inhibitor, was introduced on the market. However, when safety reports from patients on extended prophylaxis after major orthopedic surgery indicated a risk of liver toxicity it was eventually withdrawn (Kenne et al 2008). Since then several other oral anticoagulant compounds have been developed and they are currently undergoing clinical evaluation in orthopedic surgery 
(Eriksson et al 2005, 2007a; Lassen et al 2007a). One of these is rivaroxaban (Xarelto ${ }^{\circledR}$; Bayer HealthCare), a direct factor Xa (FXa) inhibitor (Perzborn et al 2005).

\section{Review of pharmacology, mode of action, pharmacokinetics of factor $\mathrm{Xa}$ inhibitors}

Activation of factor $\mathrm{X}$ to FXa initiates the conversion of prothrombin to thrombin which leads to conversion of fibrinogen to fibrin and eventually clot formation (Figure 1). An invasive operative procedure cannot be performed without tissue damage resulting in release of tissue factor (TF). Orthopedic surgery due to surgical damage to bone is especially prone to TF release because bone marrow is rich in TF (Dahl et al 1995). In conjunction with factor VIIa, TF activates FXa directly (the extrinsic pathway) or via propagation of the tenase complex (factor VIIIa + factor IXa) on an activated platelet membrane (the intrinsic pathway) (Mann et al 2003). The prothrombinase complex is then formed on the platelet surface and incorporation of FXa into this complex increases the rate of thrombin generation tremendously. The thrombingenerating efficacy of the prothrombinase complex is much more pronounced than that of free FXa (Mann et al 1998; Rauch and Nemerson 2000; Mann et al 2003a). Thus, FXa is the pivotal point in the coagulation cascade because it can be activated both by the extrinsic and the intrinsic pathways; furthermore the only function of FXa in the coagulation process is to promote coagulation and to amplify the events. Thus, it has been estimated that one molecule of FXa catalyzes the formation of $\sim 1000$ thrombin molecules (Mann et al 2003b). In the design of new antithrombotic drugs it therefore seems attractive to target the mode of action towards inhibition of FXa. Unfractionated heparin (UFH) and LMWH are indirect FXa inhibitors because they inhibit FXa by potentiation of the natural inhibitory action of antithrombin (AT) that is an endogeneous plasma protein. In addition especially UFH also has an inhibitory action on several other coagulation factors among which factor IIa is the most important. Fondaparinux is a synthetic pentasaccharide with the same mode of action as UFH and LMWH, but in contrast to those it acts solely by the antithrombin-mediated inhibition of FXa (Samama and Gerotziafas 2003). On the contrary, direct FXa inhibitors, including rivaroxaban, do not need AT to exert their inhibitory action on FXa, because they are able to bind directly to the active site of FXa, thereby preventing interaction with its substrates. As a consequence the direct FXa inhibitors are able to inhibit both free FXa and FXa bound in the prothrombinase complex (Perzborn 2005) (Figure 1).

Rivaroxaban belongs to a new group of oral direct FXa inhibitors. The chemical structure is shown in Figure 2 and

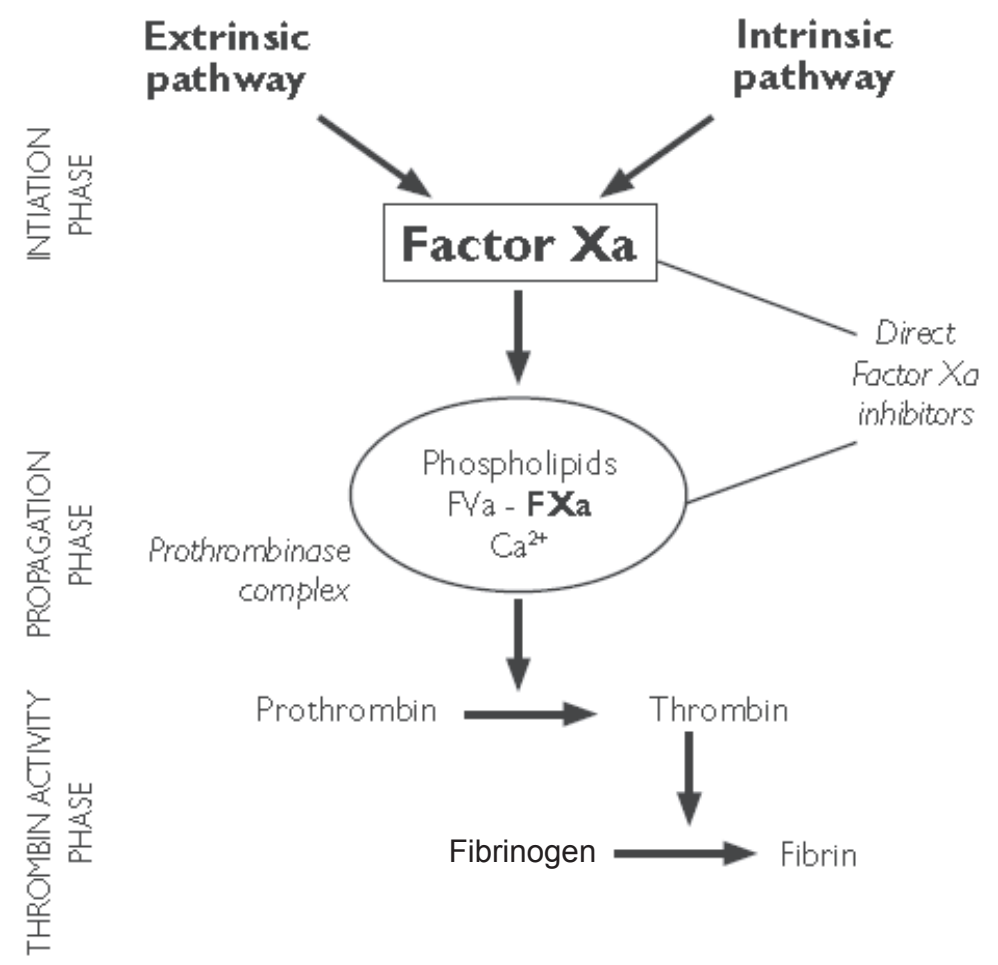

Figure I Schematic represention of the coagulation cascade with indication of mechanism of action of direct FXa inhibitors. Reproduced with permission from Bayer HealthCare. 


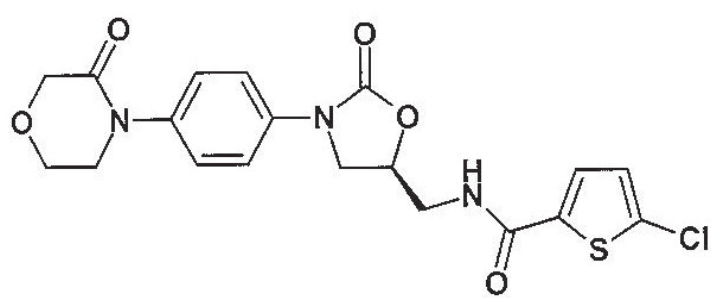

Figure 2 Chemical structure of rivaroxaban. Reproduced with permission from Bayer HealthCare.

pharmacologic features are listed in Table 1. The absorption after oral intake is near $100 \% . \mathrm{C}_{\max }$ is reached within $2-4$ hours (Kubitza et al 2005a) and is slightly enhanced by food intake, irrespective of type of food (Kubitza et al 2006a). The bioavailability is near $80 \%$ (Kubitza et al 2005b). The elimination is unchanged via the renal and the fecal/biliary routes (Kubitza and Haas 2006).

\section{Preclinical studies}

In vitro studies have shown that rivaroxaban can inhibit both free FXa and FXa bound in the prothrombinase complex more potently in human and rabbit plasma than in rat plasma. The antithrombotic effect of rivaroxaban has also been studied in vivo in rat and rabbit models. In a rat venous stasis model rivaroxaban reduced venous thrombosis in a dose-dependent fashion and was able to reduce arterial thrombus formation in an arteriovenous shunt in both rats and rabbits. When given in antithrombotic doses $(3 \mathrm{mg}$ per $\mathrm{kg} \mathrm{po}$ ) rivaroxaban did not affect bleeding time significantly in rats or rabbits (Perzborn et al 2005).

The pharmacokinetic and pharmacodynamic features of rivaroxaban were studied in a number of studies in healthy human subjects. In a single-dose escalation study, with placebo control, doses of rivaroxaban of 5-80 mg orally were studied in 108 male subjects. The study showed a dosedependent inhibition of FXa and an additional prolongation of prothrombin time (PT), which correlated with the plasma concentration of rivaroxaban. The new drug was well tolerated and there was no increased risk of bleeding compared with placebo (Kubitza et al 2005b). In a placebo-controlled

Table I Pharmacologic features of rivaroxaban taken orally

\begin{tabular}{ll}
\hline Absorption & $\sim 100 \%$ \\
$\mathrm{C}_{\max }$ & $2-4$ hours \\
$\mathrm{t}_{1 / 2}$ & $5-9$ hours \\
Bioavailability & $\sim 80 \%$ \\
Elimination & renal \\
& fecal/biliary \\
\hline
\end{tabular}

multiple dose escalation study, rivaroxaban doses of $5 \mathrm{mg}$ once, twice, and thrice daily, and $10 \mathrm{mg}, 20 \mathrm{mg}$, and $30 \mathrm{mg}$ twice daily were administered orally on days 0 and $3-7$. The study showed no clinically relevant influence on bleeding time after treatment for 7 days and there were no signs of accumulation at any dose. A dose-dependent prolongation of PT, activated partial thromboplastin time (aPTT), and HepTest to a similar extent to inhibition of FXa were seen, and it was suggested that the inhibition of the FXa activity of rivaroxaban can be monitored by these clotting tests or by measurement of FXa alone (Kubitza 2005a). None of the studies showed problems with tolerability or safety with any dose or dosing frequency of rivaroxaban.

A number of interaction studies in healthy subjects between rivaroxaban and commonly used drugs such as acetyl salicylic acid (ASA) and nonsteroid acetylsalicylic acids (NSAID) were performed. Concomitant use of ASA in 500 $\mathrm{mg}$ and $100 \mathrm{mg}$ doses and rivaroxaban at doses between $5 \mathrm{mg}$ and $80 \mathrm{mg}$ did not show any clinically relevant interaction (Kubitza et al 2006b). Rivaroxaban together with NSAID (naproxen) significantly increased bleeding time compared with rivaroxaban alone, but it was not clinically relevant (Kubitza et al 2007a). A comparative placebo-controlled study in 50 subjects treated with rivaroxaban or moxifloxacin (positive control) showed no prolongation of the QT-interval of rivaroxaban, and thus there is no need to monitor the QT-interval routinely in patients treated with rivaroxaban (Kubitza et al 2008).

With a half-life of 5-9 hours it would be expected that rivaroxaban should be administered at least twice daily to be effective. However, a crossover placebo-controlled study in which 12 healthy subjects received single oral doses of 5-30 mg of rivaroxaban showed that the endogenous thrombin potential was dose-dependently reduced by more than $80 \%$, compared with baseline, and that the prothrombinaseinduced clotting time in platelet-rich plasma was prolonged more than 1.8 times, both effects having a duration of 24 hours (Graff et al 2007). Thus, this would support a concept of once-daily administration. The clinical impact of these findings was further explored in the phase II program.

\section{Phase II program (dose finding)}

A series of dose-ranging studies was performed in patients undergoing THA or TKA and an overview of the results of these studies is given in Table 2. The first proof-of-principle study, which included patients undergoing THA, was an openlabel, randomized study to assess the efficacy and safety of different doses of rivaroxaban relative to a standard regimen of 
Table 2 Overview of the results of the four clinical studies in phase II (per-protocol data)

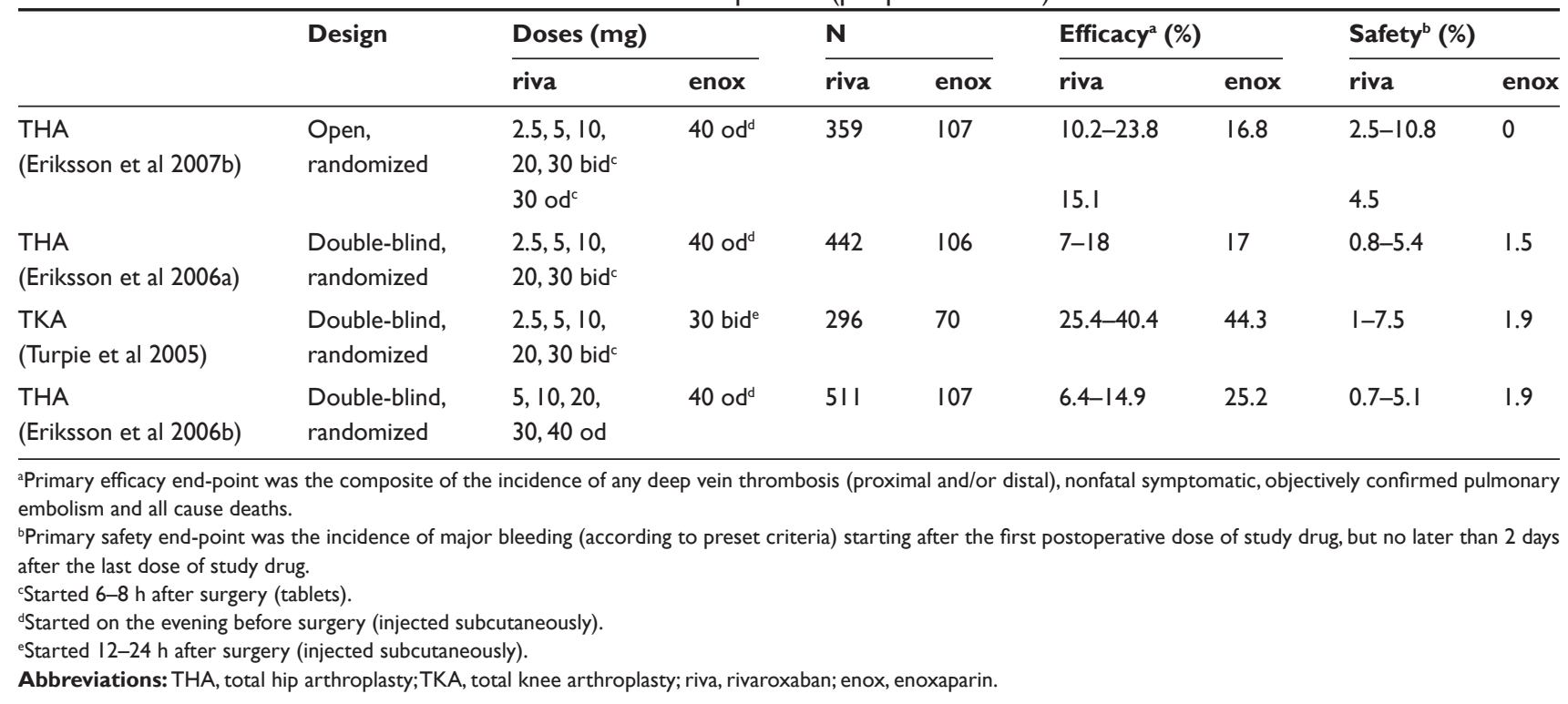

enoxaparin (Eriksson et al 2007b). Rivaroxaban was given as tablets in doses of $2.5 \mathrm{mg}, 5 \mathrm{mg}, 10 \mathrm{mg}, 20 \mathrm{mg}$, and $30 \mathrm{mg}$ twice daily and $30 \mathrm{mg}$ once daily, started 6-8 h after surgery; enoxaparin was given by subcutaneous injection of $40 \mathrm{mg}$ once daily started on the evening before surgery. The investigators were blinded to the dose of rivaroxaban, but not to the type of prophylaxis (rivaroxaban vs enoxaparin). The treatment continued for 5-9 days at which time a bilateral venography was performed to diagnose asymptomatic deep vein thrombosis (DVT); in cases of symptoms of DVT or pulmonary embolism (PE) during the study objective confirmation of the event was requested. The efficacy results with rivaroxaban were comparable with that obtained with enoxaparin, but with a flat dose response. The incidences of major bleeding were dose-dependent and at an acceptable level. In patients treated with rivaroxaban $30 \mathrm{mg}$ once daily the efficacy result was comparable with the result in the enoxaparin group (15.1\% vs16.8\%) and the incidence of major bleeding $(4.5 \%)$ was within the expected range, which was the first indication that once-daily administration of rivaroxaban could be feasible (Table 2). The next two studies to follow were randomized, double-blind studies in THA or TKA patients, respectively (Turpie et al 2005; Eriksson et al 2006a). The dose regimens of rivaroxaban were $2.5 \mathrm{mg}, 5 \mathrm{mg}$, $10 \mathrm{mg}, 20 \mathrm{mg}$, and $30 \mathrm{mg}$ administered orally twice daily started 6-8 $\mathrm{h}$ after surgery and the comparator was again subcutaneous injections of enoxaparin, $40 \mathrm{mg}$ once daily started on the evening before surgery in the THA study, and $30 \mathrm{mg}$ twice daily started 12-24 h after surgery in the TKA study. The duration of the treatment and timing of venography was the same as for the previously described study. The efficacy results obtained in both studies again showed a flat dose-response for rivaroxaban with incidences in the different dose groups that were comparable with the enoxaparin group in the individual study. The incidences of VTE in both treatment arms of the TKA study were much higher $(25.4 \%-40.4 \%$ in the rivaroxaban groups and $44.3 \%$ in the enoxaparin group) than those seen in the THA study (7\%-18\% in the rivaroxaban groups and $17 \%$ in the enoxaparin group) (Table 2), which is not surprising after knee surgery based on previous reports (Gillespie et al 2000; Geerts et al 2004). The safety results with rivaroxaban were also at a comparable level with enoxaparin and clearly dose-dependent (Table 2). A pooled analysis of the two studies showed that total daily doses of rivaroxaban of 5-20 mg had the most favorable balance between antithrombotic efficacy and safety compared with enoxaparin (Fisher et al 2007). The last study in the phase II program was performed in patients undergoing THA, and in contrast to the previous studies it was decided that rivaroxaban was to be administered once daily in all dose groups (Eriksson et al 2006b). The following once-daily doses of rivaroxaban were studied: $5 \mathrm{mg}, 10 \mathrm{mg}, 20 \mathrm{mg}, 30 \mathrm{mg}$, and $40 \mathrm{mg}$ started 6-8 $\mathrm{h}$ after surgery, and for the comparator arm enoxaparin $40 \mathrm{mg}$ injected subcutaneously once daily started on the evening before surgery was chosen. Treatment duration and timing of venography was the same as for the previously described studies. The primary efficacy end-point was observed in $6.4 \%-14.9 \%$ of patients in the different rivaroxaban dose groups, without any dose relation, and in $25.2 \%$ of the enoxaparin group; however, the study was not powered to show any 
statistical significance (Table 2 ). The primary safety end-point was observed in $0.7 \%-5.1 \%$ of patients in the rivaroxaban groups, with a significant dose-dependency, compared with $1.9 \%$ in the enoxaparin group. When compared with the safety results of the previous study in THA using twice-daily dosing of rivaroxaban the results did not differ much for total daily doses of $5 \mathrm{mg}(0.8 \%$ vs $2.3 \%), 10 \mathrm{mg}(0.7 \%$ vs $2.2 \%), 20 \mathrm{mg}(4.3 \%$ vs $2.3 \%$ ), and $40 \mathrm{mg}(5.1 \%$ vs $4.5 \%$ ) (Eriksson et al 2006a). Thus, once-daily dosing of rivaroxaban did not seem to increase the risk of bleeding compared with twice-daily dosing.

In the entire phase II program all adverse reactions observed in the treatment groups were registered. To follow the liver function repeated measurements of liver aminotransferase levels such as alanine aminotransferase (ALT), aspartate aminotransferase (AST) and bilirubin levels up to 7 days after the last dose of study medication were performed. In the second THA study in phase II (Eriksson et al 2006a) ALT or AST levels $>3$ times the upper limit of normal (ULN) occurred in $11.2 \%$ and $8.8 \%$ of patients in the enoxaparin group compared with $3.9 \%-6.4 \%$ and $3.3 \%-8.3 \%$, respectively, in the rivaroxaban groups. In the phase II TKA study (Turpie et al 2005), elevated levels of ALT and AST ( $>3 \times$ ULN) and of bilirubin ( $2 x$ ULN) were seen in 4 patients in the rivaroxaban groups. Two of these patients with elevated ALT and bilirubin remained on treatment without clinical symptoms. All changes returned to normal at follow-up. In the THA study with once-daily administration of rivaroxaban (Eriksson et al 2006b), ALT or AST levels $>3 x$ ULN occurred in $7.1 \%$ and $7.1 \%$ of patients in the enoxaparin group compared with 3.0\%-5.4\% and $3.4 \%-6.2 \%$, respectively, in the rivaroxaban groups. One patient treated with rivaroxaban $30 \mathrm{mg}$ od for 7 days showed elevation of ALT $>3 x$ ULN and bilirubin $>2 x$ ULN $3 \mathrm{~h}$ after the first drug administration. Both returned to normal at follow-up despite continued treatment. In a patient treated with rivaroxaban $10 \mathrm{mg}$ od for 7 days, who eventually had a diagnosis of cholecystolithiasis, liver enzymes continued to rise after treatment cessation. In general, none of the studies showed any dose-dependency between rivaroxaban and increased liver parameters. Based on the findings in the phase II program, however, it was not possible to determine whether there was a relationship between rivaroxaban and liver function impairment. Another open question after the phase II program was whether there was an increased risk of liver function impairment when rivaroxaban was given for thromboprophylaxis on an extended basis (up to 35 days), which was seen with ximelagatran (Kenne et al 2008).

\section{Rationale for dose selection}

In general, when a dose of any new anticoagulant has to be selected both efficacy and safety should be taken into consideration and a perfect balance is preferable. A population analysis was performed to compare the pharmacodynamics and pharmacokinetics of total daily doses of rivaroxaban of $5 \mathrm{mg}, 10 \mathrm{mg}$, and $20 \mathrm{mg}$ (Mueck et al 2006) using blood samples collected in the previously mentioned clinical phase II studies with once- or twice-daily dosing of rivaroxaban in patients undergoing THA (Eriksson et al 2006a, b). It was found that both maximum and minimum plasma concentrations of rivaroxaban were lower after once-daily compared with twice-daily administration, but with overlapping $90 \%$ confidence intervals. The pharmocokinetic properties of rivaroxaban were found to be independent of the dosing regimen (Mueck et al 2006). In a blinded, placebo-controlled study in healthy volunteers, the effect of body weight (BW) and gender on the efficacy and safety of a single $10 \mathrm{mg}$ dose of rivaroxaban were assessed. The study showed no influence of extreme $\mathrm{BW}(>120 \mathrm{~kg}$ ) compared with normal BW (70-80 kg) on the $\mathrm{C}_{\max }$ of rivaroxaban, but it was increased by $24 \%$ in female subjects weighing $50 \mathrm{~kg}$ or less, resulting in a $15 \%$ prolongation of PT; however, this result had no clinical relevance. In addition, because gender or BW did not affect the area under the curve, dose adjustment would not be necessary (Kubitza et al 2007b). Based on the rates of the primary safety end-point in the last phase II study, it was obvious that total daily rivaroxaban doses of 5-10 mg were comparable to those seen in the enoxaparin group, $0.7 \%$ and $0.8 \%$, respectively, vs $1.9 \%$. On the contrary, the rates of the primary efficacy end-point in these two rivaroxaban groups were clearly lower compared with enoxaparin, 14.9 and 10.6, respectively vs 25.2\% (Table 2) (Eriksson 2006b). Summarizing these results, it was decided that a once-daily dosage of $10 \mathrm{mg}$ of rivaroxaban should be studied in the phase III program in orthopedic surgery.

\section{Phase III program}

The clinical phase III program in orthopedic surgery was given the acronym: RECORD (ㄹegulation of $\underline{\text { Coagulation }}$

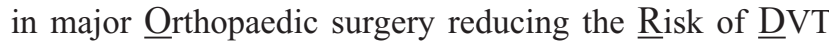
and PE). The RECORD program consists of the four clinical prophylaxis studies presented in Table 3. All studies were prospective, double blind, randomized studies comparing the antithrombotic efficacy and safety of rivaroxaban 10 $\mathrm{mg}$ given orally once daily and enoxaparin $40 \mathrm{mg}$ once daily or $30 \mathrm{mg}$ twice daily in patients undergoing THA or TKA. RECORD 1 and RECORD 2 were performed in THA 
patients and $40 \mathrm{mg}$ once daily of enoxaparin was used for comparison in both studies. In RECORD 1 both prophylactic regimens were given for a total duration of $35 \pm 4$ days (long term), whereas in RECORD 2 only rivaroxaban was given long term compared with enoxaparin which was given for 10-14 days (short term) (Table 3), because it is not universally accepted to use long-term prophylaxis after THA in spite of the recommendation in the ACCP guidelines (Geerts at el 2004). RECORD 3 and RECORD 4 were performed in TKA patients with short-term duration (10-14 days) of both regimens, because long-term prophylaxis is not recommended after TKA (Geerts et al 2004). In RECORD $3,10 \mathrm{mg}$ of rivaroxaban once daily started $6-8 \mathrm{~h}$ after surgery was compared with $40 \mathrm{mg}$ of enoxaparin started in the evening before surgery, whereas in RECORD 4 enoxaparin $30 \mathrm{mg}$ twice daily started $12-24 \mathrm{~h}$ after surgery was used in the comparator arm (Table 3 ). The efficacy results of the RECORD studies are presented in Tables 4 and 5. In all studies rivaroxaban was significantly more effective in reducing the primary efficacy end-point, the composite of the incidence of any DVT (proximal and/or distal), nonfatal symptomatic, objectively confirmed PE and all cause deaths and major VTE, the composite of proximal DVT, PE, and VTE-related death, compared with enoxaparin (Table 4). In the RECORD 2 and RECORD 3 studies, rivaroxaban also significantly reduced the incidence of symptomatic VTE events compared with enoxaparin (Table 5), which are important clinical observations. The safety (the incidence of major and/ or minor bleeding events) of rivaroxaban was comparable with enoxaparin in all the phase III studies (Table 6). The RECORD 4 study has been finalized very recently, but no results have been released yet. The liver safety parameters showed no important differences between rivaroxaban and enoxaparin, and no different action was observed on liver
Table 3 Design of the double blind, randomized phase III prophylaxis studies in orthopedic surgery

\begin{tabular}{|c|c|c|c|c|c|}
\hline \multirow[t]{2}{*}{$\begin{array}{l}\text { Study title } \\
\text { (reference) }\end{array}$} & \multirow[t]{2}{*}{ Operation } & \multicolumn{2}{|c|}{ Doses (mg) } & \multicolumn{2}{|c|}{$\begin{array}{l}\text { Duration } \\
\text { of prophylaxis } \\
\text { (days) }\end{array}$} \\
\hline & & riva & enox & riva & enox \\
\hline $\begin{array}{l}\text { RECORD I } \\
\text { (Eriksson et al } \\
2007 c \text { ) }\end{array}$ & & $10 o^{a}$ & 40 od $^{b}$ & $35 \pm 4$ & $35 \pm 4$ \\
\hline $\begin{array}{l}\text { RECORD } 2 \\
\text { (Kakkar et al } \\
2007)\end{array}$ & THA & $10 o^{a}$ & 40 od $^{\mathrm{b}}$ & $35 \pm 4$ & $10-14$ \\
\hline $\begin{array}{l}\text { RECORD } 3 \\
\text { (Lassen et al } \\
2007 b \text { ) }\end{array}$ & TKA & $10 \circ d^{a}$ & 40 od $^{b}$ & $10-14$ & $10-14$ \\
\hline RECORD 4 & TKA & $10 o^{a}$ & 30 bidc $^{c}$ & $10-14$ & $10-14$ \\
\hline
\end{tabular}

function when rivaroxaban was used for long-term prophylaxis in the RECORD 1 and RECORD 2 studies compared with short-term prophylaxis with rivaroxaban. A more detailed description of these results cannot be given because the studies have been published only in abstract form.

\section{Patient-focused perspectives such as quality of life, patient satisfaction/ acceptability}

The ideal antithrombotic is a drug with a broad therapeutic window in terms of efficacy versus safety (bleeding), with a rapid onset and offset of action, with a high bioavailability and minimal food and drug interactions after oral administration, and predictable pharmacodynamics and pharmacokinetics with

Table 4 Efficacy results in the phase III studies of the RECORD program

\begin{tabular}{|c|c|c|c|c|c|}
\hline \multirow[t]{2}{*}{ Study title (reference) } & \multirow[t]{2}{*}{$\mathbf{N}$ (randomized) } & \multicolumn{2}{|c|}{$\begin{array}{l}\text { Primary efficacy end- } \\
\text { point }^{\mathrm{a}}\left(\text { major VTE }{ }^{\mathrm{b}} \text { ) \% }\right.\end{array}$} & \multirow[t]{2}{*}{$\begin{array}{l}\text { Relative } \\
\text { risk reduction \% }\end{array}$} & \multirow[t]{2}{*}{$\begin{array}{l}\text { P-value } \\
\text { for difference }\end{array}$} \\
\hline & & riva & enox & & \\
\hline $\begin{array}{l}\text { RECORD I } \\
\text { (Eriksson et al 2007c) }\end{array}$ & $\begin{array}{l}3135 \\
(4541)\end{array}$ & $\begin{array}{l}1.1 \\
(0.2)\end{array}$ & $\begin{array}{l}3.7 \\
(2.0)\end{array}$ & $\begin{array}{l}70 \\
(88)\end{array}$ & $\begin{array}{l}<0.001 \\
(<0.001)\end{array}$ \\
\hline $\begin{array}{l}\text { RECORD } 2 \\
\text { (Kakkar et al 2007) }\end{array}$ & $\begin{array}{l}1723 \\
(2509)\end{array}$ & $\begin{array}{l}2.0 \\
(0.6)\end{array}$ & $\begin{array}{l}9.3 \\
(5.1)\end{array}$ & $\begin{array}{l}79 \\
(88)\end{array}$ & $\begin{array}{l}<0.001 \\
(<0.001)\end{array}$ \\
\hline $\begin{array}{l}\text { RECORD } 3 \\
\text { (Lassen et al 2007b) }\end{array}$ & $\begin{array}{l}1702 \\
(253 \mid)\end{array}$ & $\begin{array}{l}9.6 \\
(1.0)\end{array}$ & $\begin{array}{l}18.9 \\
(2.6)\end{array}$ & $\begin{array}{l}49 \\
(62)\end{array}$ & $\begin{array}{l}<0.001 \\
(0.016)\end{array}$ \\
\hline
\end{tabular}

aPrimary efficacy end-point was the composite of the incidence of any deep vein thrombosis (DVT) (proximal and/or distal), nonfatal symptomatic, objectively confirmed pulmonary embolism (PE) and all cause deaths.

'Major venous thromboembolism (VTE): the composite of proximal DVT-, PE-, andVTE-related death.

Abbreviations: riva, rivaroxaban; enox, enoxaparin. 
Table 5 Symptomatic venous thromboembolic (VTE) events in the phase III studies of the RECORD program

\begin{tabular}{|c|c|c|c|c|}
\hline \multirow[t]{2}{*}{$\begin{array}{l}\text { Study title } \\
\text { (reference) }\end{array}$} & \multicolumn{2}{|c|}{$\begin{array}{l}\text { Symptomatic } \\
\text { VTE }{ }^{\mathrm{a}} \mathrm{n} / \mathrm{N}(\%)\end{array}$} & \multirow[t]{2}{*}{$\begin{array}{l}\text { Relative risk } \\
\text { reduction \% }\end{array}$} & \multirow[t]{2}{*}{$\begin{array}{l}\text { P-value for } \\
\text { difference }\end{array}$} \\
\hline & riva & enox & & \\
\hline $\begin{array}{l}\text { RECORD I } \\
\text { (Eriksson et al } \\
\text { 2007c) }\end{array}$ & $\begin{array}{l}6 / 2195 \\
(0.3)\end{array}$ & $\begin{array}{l}I I / 2206 \\
(0.5)\end{array}$ & - & 0.22 \\
\hline $\begin{array}{l}\text { RECORD } 2 \\
\text { (Kakkar et al } \\
2007)\end{array}$ & $\begin{array}{l}3 / 1212 \\
(0.2)\end{array}$ & $\begin{array}{l}\text { I5/I } 207 \\
(I .2)\end{array}$ & 80 & 0.004 \\
\hline $\begin{array}{l}\text { RECORD } 3 \\
\text { (Lassen et al } \\
\text { 2007b) }\end{array}$ & $\begin{array}{l}8 / I 20 I \\
(0.7)\end{array}$ & $\begin{array}{l}24 / 1217 \\
(2.0)\end{array}$ & 66 & 0.005 \\
\hline
\end{tabular}

aSymptomatic VTE = objectively verified deep vein thrombosis and/or pulmonary embolism occurring during the study

Abbreviations: riva, rivaroxaban; enox, enoxaparin.

no requirement for dose adjustment and coagulation monitoring. For the patient, such a drug would be easy to handle in everyday life, and therefore patient acceptability would be easily obtained. When we consider the clinical behavior of rivaroxaban in phase II and III it seems that it comes close to this ideal. However, there are still some outstanding questions to be resolved, such as the influence of impaired renal function on drug safety, the lack of an antidote in case of a bleeding event, and patients with nausea and vomiting after surgery being unable to take the medication as planned, and patients with indwelling epidural catheters. Based on previous experience, the cost-effectiveness of a new drug compared with existing alternatives is also important for clinicians deciding whether to use a new drug. Competition from other new drugs

Table 6 Safety results of the phase III studies in the RECORD program

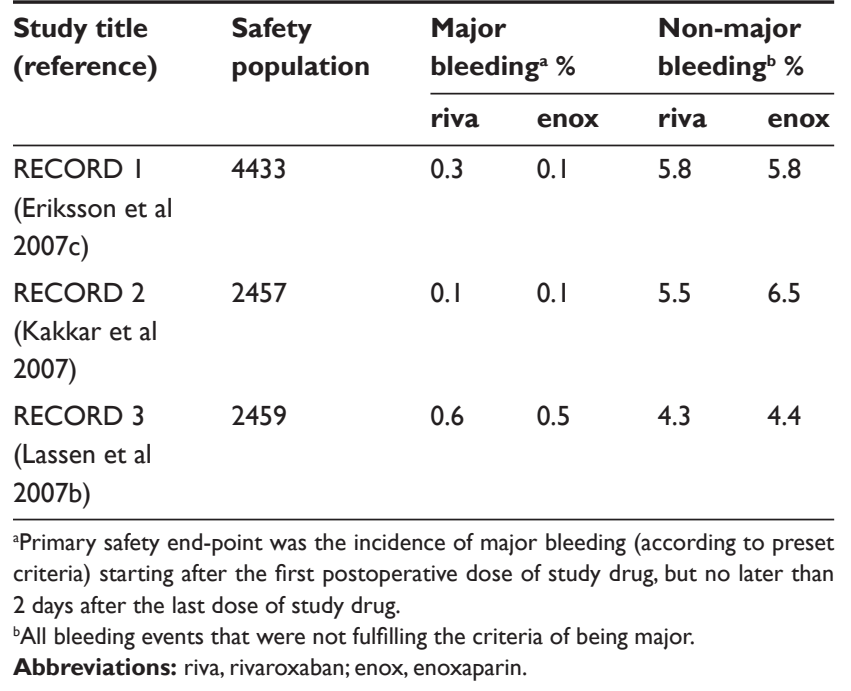

on the market is also important. Dabigatran etexilate, an oral direct thrombin inhibitor, has recently been approved in Europe for thromboprophylaxis in orthopedic settings. In a recent prospective study, dabigatran etexilate was as effective and safe as enoxaparin $40 \mathrm{mg}$ od in reducing the risk of VTE after THA (Eriksson et al 2007d). Within the near future it will be settled if both drugs will be approved and then only a direct comparison in a relevant clinical study can show which of the drugs that has the most profitable efficacy and safety.

\section{Conclusions, therapeutic potential}

Rivaroxaban - an oral, direct FXa inhibitor - is a new compound for VTE prophylaxis after orthopedic surgery. The drug has predictable pharmacokinetics and pharmacodynamics and needs no coagulation monitoring or dose adjustment. Results from phase II and phase III clinical studies have shown that rivaroxaban, at a once-daily dosage of $10 \mathrm{mg}$, has a significantly better efficacy and a comparable safety compared with enoxaparin in patients undergoing THA and TKA.

\section{Disclosures}

The author has received consultancy fees from Bayer Healthcare, BMS, and Sanofi Aventis.

\section{References}

Bergqvist D, Johnsson B. 1999. Cost-effectiveness of prolonged administration of a low molecular weight heparin for the prevention of deep venous thrombosis following hip replacement. Value Health, 2:288-94.

Dahl OE, Aspelin T, Lyberg T. 1995. The role of bone traumatization in the initiation of proximal deep vein thrombosis during cemented hip replacement surgery in pigs. Blood Coagul Fibrinolysis, 6:709-17.

Eriksson BI, Dahl OE, Büller HR, et al. 2005. A new oral direct thrombin inhibitor, dabigatran etexilate, compared with enoxaparin for prevention of thromboembolic events following total hip or knee replacement: the BISTRO II randomized trial. J Thromb Haemost, 3:103-11.

Eriksson BI, Borris L, Dahl OE, et al. 2006a. Oral, direct Factor Xa inhibition with BAY 59-7939 for the prevention of venous thromboembolism after total hip replacement. $J$ Thromb Haemost, 4:121-8.

Eriksson BI, Borris LC, Dahl OE, et al. 2006b. A once-daily, oral, direct Factor Xa inhibitor, rivaroxaban (BAY 59-7939), for thromboprophylaxis after total hip replacement. Circulation, 114:2374-81.

Eriksson BI, Turpie AGG, Lassen MR, et al. 2007a. A dose escalation study of YM 150, an oral direct factor Xa inhibitor, in the prevention of venous thromboembolism in elective primary hip replacement surgery. J Thromb Haemost, 5:1660-5.

Eriksson BI, Borris LC, Dahl OE, et al. 2007b. Dose-escalation study of rivaroxaban BAY 59-7939 - an oral, direct Factor Xa inhibitor- for the prevention of venous thromboembolism in patients undergoing total hip replacement. Thromb Res, 120:685-93.

Eriksson BI, Borris LC, Friedman RJ, et al. 2007c. Oral rivaroxaban compared with subcutaneous enoxaparin for extended thromboprophylaxis after total hip arthroplasty: The RECORD 1 trial. Blood, 110:Abstract \#6.

Eriksson BI, Dahl OE, Rosencher N, et al. 2007d. Dabigatran etexilate versus enoxaparin for prevention of venous thromboembolism after total hip replacement: a randomised, double-blind, non-inferiority trial. Lancet, 370:949-56. 
Geerts WH, Pineo GF, Heit JA, et al. 2004. Prevention of venous thromboembolism. The seventh ACCP conference on antithrombotic and thrombolytic therapy. Chest, 126:338S-400S.

Fisher WD, Eriksson BI, Bauer KD, et al. 2007. Rivaroxaban for thromboprophylaxis after orthopaedic surgery: Pooled analysis of two studies. Thromb Haemost, 97:931-7.

Gillespie W, Murray D, Gregg PJ, et al. 2000. Risks and benefits of prophylaxis against venous thromboembolism in orthopaedic surgery. J Bone Joint Surg, 82-B:475-9.

Graff J, von Hentig N, Misselwitz F, et al. 2007. Effects of the Oral, Direct Factor Xa Inhibitor Rivaroxaban on Platelet-Induced Thrombin Generation and Prothrombinase Activity. J Clin Pharmacol, 47: 1398-407.

Kakkar AK, Brenner B, Dahl OE, et al. 2007. Extended thromboprophylaxis with rivaroxaban compared with short-term thromboprophylaxis with enoxaparin after total hip arthropæasty: The RECORD 2 trial. Blood, 110:Abstract \#307.

Kenne K, Skanberg I, Glinghammar B, et al. 2008. Prediction of druginduced liver injury in humans by using in vitro methods: The case of ximelagatran. Toxicol In Vitro, doi:10.1016/j.tiv.2007.11.014.

Kubitza D, Becka M, Wensing G, et al. 2005a. Safety, pharmacodynamics and pharmacokinetics of BAY 59-7939 an oral, direct factor Xa inhibitor after multiple dosing in healthy male subjects. Eur J Clin Pharmacol, 61:873-80.

Kubitza D, Becka M, Voith B, et al. 2005b. Safety, pharmacodynamics, and pharmacokinetics of single doses of BAY 59-7939, an oral, direct factor Xa inhibitor. Clin Pharmacol Ther, 78:412-21.

Kubitza D, Becka M, Zuehlsdorf M, et al. 2006a. Effect of food, an antacid, and the $\mathrm{H}_{2}$ antagonist ranitidine on the absorption of BAY 59-7939 (rivaroxaban), an oral, direct factor Xa inhibitor, in healthy subjects. $J$ Clin Pharmacol, 46:549-58.

Kubiza D, Becka M, Mueck W, et al. 2006b. Safety, tolerability, pharmacodynamics, and pharmacokinitics of rivaroxaban - an oral, direct factor Xa inhibitor - are not affected by aspirin, J Clin Pharmacol, 46:981-90.

Kubitza D, Haas S. 2006. Novel factor Xa inhibitors for prevention and treatment of thromboembolic diseases. Expert Opin Investig Drugs, 15:843-55.

Kubitza D, Becka M, Mueck W, et al. 2007a. Rivaroxaban (BAY 59-7939) an oral, direct factor Xa inhibitor - has no clinically relevant interaction with noproxen, Br J Clin Pharmacol, 63:469-76.
Kubitza D, Becka M, Zuehlsdorf M, et al. 2007b. Body weight has limited influence on the safety and tolerability, pharmacokinetics, or pharmacodynamics of rivaroxaban (BAY 59-7939) in healthy subjects, J Clin Pharmacol, 47:218-26.

Kubitza D, Mueck W, Becka M, 2008. Randomized double-blind, crossover study to investigate the effect of rivaroxaban on QT-interval prolongation. Drug Saf, 31:67-77.

Lassen MR, Davidson BL, Gallus A, et al. 2007a. The efficacy and safety of apixaban, an oral, direct factor Xa inhibitor, as thromboprophylaxis in patients following total knee replacement. J Thromb Haemost, 5:2368-75.

Lassen MR, Turpei AGG, Rosencher N, et al. 2007b. Rivaroxaban - an oral direct factor Xa inhibitor - for thromboprophylaxis after total knee arthroplasty: The RECORD 3 trial. Blood, 110:Abstract \#308.

Mann KG, van Veer C, Cawtern K, et al. 1998. The role of the tissue factor pathway in inhibition of coagulation. Blood Coagul Fibrinolysis, 9(Suppl 1):S3-S7.

Mann KG, Butenas S, Brummel K. 2003a. The dynamics of thrombin formation. Arterioscler Thromb Vasc Biol, 23:17-25.

Mann KG, Brummel K, Butenas S. 2003b. What is all that thrombin for? $J$ Thromb Haemost, 1:1504-14.

Mueck W, Eriksson BI, Borris LC et al. 2006. Rivaroxaban for thromboprophylaxis in patients undergoing total hip replacement: comparison of pharmacokinetics and pharmacodynamics with once- and twice-daily dosing. Blood, 108:Abstract 903.

Perzborn E, Strassburger J, Wilmen A, et al. 2005. In vitro and in vivo studies of the novel antithrombotic agent BAY 59-7030 - an oral, direct factor Xa inhibitor. J Thromb Haemost, 3:514-21.

Rauch U, Nemerson Y. 2000. Circulating tissue factor and thrombosis. Curr Opin Hamatol, 7:273-7.

Samama MM, Gerotziafas GT. 2003. Evaluation of the pharmacological properties and clinical results of the synthetic pentasaccharide (fondaparinux). Thromb Res, 109:1-11.

Turpie AGG, Fisher WD, Bauer KA, et al. 2005. BAY 59-7939: an oral, direct Factor $\mathrm{Xa}$ inhibitor for the prevention of venous thromboembolism in patients after total knee replacement. A phase II dose-ranging study. J Thromb Haemost, 3:2479-86. 